\title{
Activities of MSCs Derived from Transgenic Mice Seeded on ADM Scaffolds in Wound Healing and Assessment by Advanced Optical Techniques
}

\author{
Ning Wang ${ }^{\mathrm{a}}$ Hanping Liu ${ }^{\mathrm{a}} \quad$ Xuefeng Lib ${ }^{\mathrm{b}}$ Qilei Zhang ${ }^{\mathrm{b}}$ Maosheng Chen ${ }^{\mathrm{a}}$ Ying Jin $^{\mathrm{a}}$ \\ Xiaoyuan Denga \\ aMOE Key Laboratory of Laser Life Science, College of Biophotonics, South China Normal University, \\ Guangzhou, 'bollege of Life Science, South China Normal University, Guangzhou, China
}

\section{Key Words}

Cutaneous wound healing • MSCs • GFP-labeling • ADM scaffolds • SHG-TPEF imaging

\begin{abstract}
Background/Aims: Bone marrow Mesenchymal stem cells (MSCs) are promising for promoting cutaneous wound healing through reinforcing cellular processes. We evaluated the effect of GFP-tagged MSCs transplantation on skin regeneration in excisional wounds in mice. Methods: MSCs from GFP-labeled transgenic mice were co-cultured with acellular dermal matrix (ADM) scaffolds, and MSC-ADM scaffolds were transplanted into surgical skin wounds of BALB/c mice. After implantation, the survival and behavior of MSCs were examined by second harmonic generation and two-photon excitation fluorescence imaging, western blotting and DNA amplification and sequencing. Results: GFP-tagged MSCs were retained inside the regenerating skin until day 14 post-transplantation. Alpha-smooth muscle actin $(\alpha-S M A)$ and vimentin (VIM) were detected at 3, 5, 7, and 14 days post-transplantation by immunofluorescence double labeling. Although the $\mathrm{GFP}^{+} / \alpha-\mathrm{SMA}^{+}-$and $\mathrm{GFP}^{+} / \mathrm{VIM}^{+}$-cell numbers decreased gradually with healing time, $\alpha-\mathrm{SMA}^{+}$- and $\mathrm{VIM}^{+}$-cell numbers significantly increased, most of them were endogenous functional cells which were related to angiogenesis and collagen fiber structural remodeling. Conclusion: Therefore, in the initial stage of wound healing, transplanted MSCs differentiated into functional cells and played paracrine roles to recruit more endogenous cells for tissue remodeling. With the disappearance of exogenous cells, endogenous cells were responsible for the latter stage of cutaneous wound healing.
\end{abstract}

(C) 2017 The Author(s)

Published by S. Karger AG, Basel

\section{Introduction}

Mesenchymal stem cells (MSCs) derived from extensive sites in adult, perinatal, or fetal tissues are considered alternative candidates for cell-based regenerative therapy due to their potential influence on the wound microenvironment. In dermatology, various of molecules 


\section{Cellular Physiology Cell Physiol Biochem 2017;42:623-639

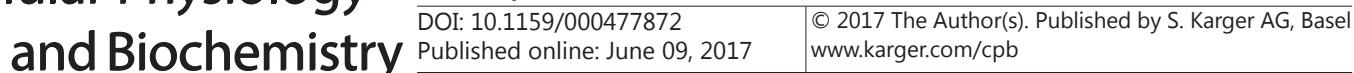 \\ Wang et al.: Activities and Assessment of MSCs in Wound Healing by Advanced Optical Techniques}

and signaling pathways are considered significant for cutaneous wound healing $[1,2]$. Many studies have revealed that MSCs enhance cutaneous wound healing by accelerating cell migration and wound closure [3-9], increasing angiogenesis [10-12], modulating inflammation [13-15] and promoting re-epithelialization and extracellular matrix (ECM) remodeling [16-18]. Although the therapeutic potential of MSCs has been shown during cutaneous wound healing, optimizing the delivery of MSCs needs to be further investigated. Intravenous injection of MSCs or intradermal injection of MSCs into or around the wound site represent major limiting factors due to poor engraftment efficiency and cell retention at the wound area $[19,20]$. To overcome this limitation, acellular dermal matrix (ADM) scaffolds as a 3-dimensional allogeneic collagen carrier have been widely used in wound repair and tissue defect repair [21]. ADM scaffolds are characterized by a mixture of collagen as the main component, which is highly similar to the structure of the skin dermis, is less immunogenic because of the removal of cellular components, and provides mechanical strength. This ADM scaffold provides a living space that is similar to the microenvironment of real skin, which is conducive for cell adhesion, migration, proliferation and growth, to promote wound healing [22-24]. Therefore, we also used ADM scaffolds as the delivery method for MSCs in the present study.

As a new imaging method with many unique advantages, nonlinear optical imaging technology is widely used in biomedical and other fields, especially for tracking cell behaviors and monitoring collagen remodeling during wound healing in vivo $[25,26]$. Two-photon excitation fluorescence (TPEF) and second harmonic generation (SHG) are nonlinear optical processes. For imaging the internal composition of biological tissue, TPEFSHG imaging depends on the signal sources of second-harmonic and two-photon-excited fluorescence, which is produced by the nonlinear optical effect as a result of the interactions of a strong near-infrared femtosecond laser and biological tissue [27]. TPEF is a two-photon absorption process and fluorescence emits from excited endogenous fluorescent substances or fluorescent proteins. Two-photon fluorescence signals are based on simultaneous twophoton absorptions which can only highly occur within focal layers, thus provide highresolution and three-dimensional images. While SHG is the process of coherent scattering. In nonlinear scattering effects, photons are not absorbed by a biological sample and the toxicity and bleaching effects can be eliminated. SHG can be used to track physiological processes of tissues over a long period without affecting their normal function and growth. In addition, specific intrinsic structures of biological tissue can induce strong SHG signals, which can avoid the need to use dyes that are associated with light toxicity. For example, the collagen fibers in the dermal matrix can induce a strong intrinsic SHG signal $[28,29]$. The combination of TPEF-SHG provides an ideal setting for in vivo monitoring of the change in collagen and $\mathrm{ECM}$ and for tracing the presence of $\mathrm{GFP}^{+}$-MSCs during wound healing.

It is essential to label MSCs with a stable fluorescent tag to trace their behavior at the wound site using advanced TPEF-SHG imaging techniques. Our previous studies demonstrated that no fluorescent signals were detected in healing tissue 14 days after MSC-ADM scaffolds implantation [30,31]. We speculated as to whether the different labeling modes might affect the stability of GFP expression in MSCs during the progression of wound healing. In this study, instead of using commercial MSCs expressing GFP by lentiviral transfection, MSCs derived from the bone marrow of transgenic mice were utilized to assess the retention and functional role of MSCs at different periods of the wound healing process.

\section{Materials and Methods}

\section{Ethics statement}

All experimental protocols were approved by the Ethical Committee for Animal Experiments of South China Normal University. All animal experiments conducted in this research were performed in accordance with the guidelines of South China Normal University Intramural Animal Use and Care Committee and met the NIH guidelines for the care and use of laboratory animals.

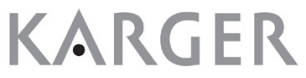




\section{Animals}

GFP-labeled transgenic C57BL/6 mice (4 weeks old) were purchased from Cyagen Biosciences, Guangzhou, China. Male BALB/c mice (8-10 weeks old) were purchased from the Experimental Animal Center of Southern Medical University (Guangzhou, China). The mice were housed in polypropylene cages under standard conditions and provided food and water ad libitum.

\section{Preparation of fluorescent mouse organs}

The mice were sacrificed by cervical dislocation and then soaked in alcohol for 3-5 min for sterilization. Then, the back hair was removed, and the mice were fixed on an operating table. The full thickness of the skin was removed using scissors sterilized with alcohol and was then stored in liquid nitrogen. Subsequently, the abdominal cavity of the mice was opened, and the heart, liver, kidneys and lungs were carefully removed. Finally, we collected muscle tissue from the inside and outside of the mouse thigh, tongue from the oral cavity, and brain from the brain cavity. All these isolated tissue samples and organs were stored in liquid nitrogen.

\section{Isolation and culture of transgenic mouse MSCs}

MSCs were isolated from bone marrow harvested from the femurs and tibias of male GFP transgenic mice according to the method described previously [32]. The marrow was cultured in OriCellTM mouse MSC Growth Medium (MUCMX-90011, Cyagen Bioscience, Guangzhou, China) at $37^{\circ} \mathrm{C}$ under 5\% CO2. After culturing for $48 \mathrm{~h}$, unattached cells were removed, and the medium was changed regularly every 3 days. Cell passage was carried out when the adherent cells reached $90 \%$ confluence.

\section{Flow cytometry}

Flow cytometry assays for cell surface antigens CD34, CD29, CD90, CD45, CD105, CD44 and CD14 of mouse MSCs were performed according to previously described methods [33]. Passage 3 MSCs were re-suspended and dissociated into single-cell suspensions. The cell concentration of the suspensions was adjusted to $10^{6}$ cells $/ \mathrm{mL}$, and then the suspension was packaged into eight 1.5-mL EP tubes. After adding fluorescein isothiocyanate (FITC)-or phycoerythrin-conjugated monoclonal antibodies specific for CD34, CD45, CD29, CD90, CD105, CD44 and CD14, the suspension cells were incubated at $4^{\circ} \mathrm{C}$ for $30 \mathrm{~min}$, washed with PBS, and subjected to flow cytometry analysis.

\section{Preparation of acellular dermal scaffold}

ADM scaffolds were obtained from 10-week-old male BALB/c mouse full-thickness skin [30]. The donor mice were injected intraperitoneally with $0.5 \%$ chloral hydrate. The back hair trimmed as much as possible, and small pieces of skin $\left(3 * 5 \mathrm{~mm}^{2}\right)$ were removed from the mice. The skin tissues were washed with PBS and treated with $0.25 \%$ dispase (Aoboxing, Beijing, China) at $4^{\circ} \mathrm{C}$ for $48 \mathrm{~h}$ to remove residual hair and the epidermis. After washing with PBS, the skin samples were soaked in $0.03 \%$ Triton solution and shaken for $24 \mathrm{~h}$ in a horizontal shaker at an appropriate speed (70-80 rpm). This process was repeated to ensure removal of cellular components in the matrix. Acellular scaffolds were treated by ultrasonic oscillation to remove the grease of the scaffolds and dehydrated in ethanol (50\%, 75\%, and 100\%), chloroform, and ethanol (100\%, 75\%, and 50\%) for $30 \mathrm{~min}$ each. Finally, the samples were stored in distilled water at $4^{\circ} \mathrm{C}$ until use.

\section{Scanning electron microscopy (SEM) imaging of ADM scaffolds}

The ADM scaffolds were critical-point dried with liquid carbon dioxide and then sputtered with a 30nm gold layer. SEM images of the samples were taken using a scanning electron microscope (Zeiss Ultra 55, Carl Zeiss, Jena, Germany). These images were used to analyze the structure and arrangement of collagen in the ADM scaffolds.

\section{Seeding of MSCs on the ADM scaffolds}

ADM scaffolds were washed with PBS three times, placed in a 48-well plate (one piece per well) with the dermis layer side up, and incubated with OriCellTM mouse MSC growth medium (MUCMX-90011, Cyagen Bioscience, Guangzhou, China) for $>24$ h. Then, MSCs $\left(1 \times 10^{5}\right)$ were seeded in each well and cultured in the MSC growth medium. The culture medium was replaced on the second day. On the third day, most of the MSCs had attached to the ADM scaffolds, and the MSC-ADM complexes were transplanted into mouse skin wounds. 


\section{Cellular Physiology Cell Physiol Biochem 2017;42:623-639 \\ \begin{tabular}{ll|l} 
DOI: 10.1159/000477872 & Cond Biochemistry & $\begin{array}{l}\text { O } 2017 \text { The Author(s). Published by S. Karger AG, Basel } \\
\text { www.karger.com/cpb }\end{array}$
\end{tabular}}

Wang et al.: Activities and Assessment of MSCs in Wound Healing by Advanced Optical Techniques

\section{TPEF-SHG imaging of ADM and MSC-ADM grafts in vitro}

The MSC-ADM scaffolds were gently washed in PBS to remove dead and non-adherent cells, fixed in 10\% formalin, stained with 4',6-diamidino-2-phenylindole (DAPI,,28718-90-3,sigma, USA) for 15 min and washed 5 times with PBS to observe the nuclei of the MSCs. Images of the grafts were taken by a two-photon laser scanning confocal microscope (TPLSCM, LSM 710 NLO, Carl Zeiss, Jena, Germany) using the stack scan with the laser (Coherent, Santa Clara, CA, USA) at wavelengths of $720 \mathrm{~nm}$ (DAPI imaging), $850 \mathrm{~nm}$ (GFP imaging) and $820 \mathrm{~nm}$ (collagen imaging). The imaging system scanned the ADM and MSC-ADM scaffolds continually, and a series of focal planes were obtained along the $\mathrm{Z}$ axis with a 1- $\mu \mathrm{m}$ step size. GFP, DAPI and collagen imaging were performed in each of the three-dimensional image acquisition experiments.

\section{Excision wound model and MSC-ADM implantation}

A full-thickness, 7-mm-diameter skin wound was sheared on the middle dorsum of anesthetized male BALB/c mice (8-10 week) using a biopsy punch. Then, the MSC-ADM scaffolds were transplanted into the wounds of the recipient mice. We removed the excess liquid components around the wound with filter paper and covered the wound area with Comfeel transparent dressing. Finally, the wound was wrapped with medical adhesive tape. The wounds in control group meant no any treatment of ADM scaffold and MSCs, besides the usage of Comfeel transparent dressing and medical adhesive tape.

\section{TPEF-SHG imaging of MSC-ADM transplanted into the wound site ex vivo}

Mice were anesthetized with chloral hydrate solution after treatment for 3, 5, 7 and 14 days. The cutaneous wound repair areas were disinfected with alcohol and dissected from the mice, flattened and placed on clean glass slides. These tissue samples were imaged in stack scan mode by TPLSCM with a laser at wavelengths of $850 \mathrm{~nm}$ (GFP imaging) and $820 \mathrm{~nm}$ (collagen imaging). During the imaging process, the inner side of the wound areas in each sample were scanned continuously (a frame of a 2D image) for collagen and GFP simultaneously at a speed of $10 \mathrm{~s}$ per frame. To ensure the selected tissue samples were alive, the exposure time of the samples was limited to within $30 \mathrm{~min}$. The intensities of the SHG signals were collected and analyzed using Image J software.

\section{Western Blotting}

Eight organs from the transgenic mouse were lysed in radioimmunoprecipitation assay (RIPA) buffer and PMSF. The total proteins were resolved by SDS-PAGE, then transferred onto immunoblot membranes [poly (vinylidene difluoride)]. According to the instructions of Marker molecular weight, immunoblot membranes were cut into two parts, one of which contains GFP, another contains GAPDH. The membranes were blocked in $5 \%$ skim milk at $4^{\circ} \mathrm{C}$ overnight and incubated with rabbit monoclonal GFP antibody (1:2000 dilution, Millipore Chemicon, Billerica, MA, USA) and mouse monoclonal GAPDH antibody (1:2000 dilution, CW0100A, cwbiotech, Beijing, China) at $4^{\circ} \mathrm{C}$ overnight. After washing the blots three times with TBS-buffered saline with $0.05 \%$ Tween-20 (TBST), they were incubated with secondary antibodies for horseradish peroxidase (HRP)-conjugated goat anti-rabbit GFP IgG (1:3000 dilution, CW0103, cwbiotech, Beijing, China) and goat anti-mouse GAPDH IgG (1:3000 dilution, CW01025, cwbiotech, Beijing, China) at room temperature for two hours. The blots were washed three times and visualized using a 3, 3'-diaminobenzidine (DAB) system (CW0125B, Qiyun Biotechnology, Guangzhou, China). The membranes were scanned and photographed using an MP ChemiDoc versatile gel imaging analysis system. Signal intensity was quantified and analyzed using a Quantity One analysis system (Bio-Rad).

mRNA expression by real-time quantitative PCR

The organs of the transgenic mice were ground and washed three times in warm PBS. Then, the total RNA was extracted from the tissues using RNAiso Plus (D9108A, Bao Biological Engineering, Dalian, China) and purified by DNase treatment. RNA was converted to cDNA, and quantitative real-time PCR was performed according to the manufacturer's instructions (Applied Biosystems 7500). The q-PCR primer sequences were as follows: green fluorescent protein (GFP) forward 5'-GCACGACTTCTTCAAGTCCGCCATGCC-3', reverse 5'-GCGGATCTTGAAGTTCACCTTGATGCC-3'. Reactions were performed using SYBR Green PCR master mix in a Bio-Rad iCycler iQ Detection System. The expression levels of the mRNA of GFP genes were normalized according to the reference gene ACTB. Normalization and fold changes were calculated using the $\Delta \Delta \mathrm{Ct}$ method [34]. The skin of normal healthy mice was used as a control group. Five repetitions were performed on each sample. 


\section{DNA amplification and product identification}

Skin samples were harvested on the 14,21, and 28 days after treatment. The total DNA of these samples was extracted by using a TIANamp Genomic DNA kit (N1141, Dongsheng Biotech, Guangzhou, China). The content and purity of the extracted DNA were measured using an Ultra Micro spectrophotometer. The DNA was amplified with the following GFP primers: forward 5'-GCACGACTTCTTCAAGTCCGCCATGCC-3', reverse 5'-GCGGATCTTGAAGTTCACCTTGATGCC-3', in a 25- $\mu \mathrm{L}$ reaction mixture containing $2.5 \mu \mathrm{L}$ PCR buffer, $4.0 \mu \mathrm{L}$ dNTP, $0.5 \mu \mathrm{L} \mathrm{Mg2+,} 1.0 \mu \mathrm{L}$ template DNA, $0.25 \mu \mathrm{L}$ Taq enzyme, $1.0 \mu \mathrm{L}$ each of upstream and downstream primers, and $14.75 \mu \mathrm{L}$ Sterile distilled water (dd H20). The cycling parameters were as follows: predenaturation at $95^{\circ} \mathrm{C}$ for $3 \mathrm{~min} ; 35$ cycles of denaturation at $95^{\circ} \mathrm{C}$ for $45 \mathrm{~s}$, annealing at $50^{\circ} \mathrm{C}$ for $45 \mathrm{~s}$, and extension at $72^{\circ} \mathrm{C}$ for $45 \mathrm{~s}$; full extension at $72^{\circ} \mathrm{C}$ for $10 \mathrm{~min}$ and holding at $4^{\circ} \mathrm{C}$ until the end. After the PCR amplification reaction, a $4-\mu \mathrm{L}$ amplification product was mixed with $1 \mu \mathrm{L} 10 \times$ loading buffer, loaded onto $1 \%$ agarose gels, and electrophoresed for 15 min under $135 \mathrm{~V}$. Then, the gels were photographed using a gel imaging system. Marker D2000 was used as a standard reference to determine the size of the amplified DNA products. Finally, the PCR products were sent to Meiji Biological Engineering Co. Ltd. (Shanghai, China) for DNA sequencing.

Histological and immunofluorescent analysis

Wound samples were fixed in $4 \%$ polyformaldehyde at $4^{\circ} \mathrm{C}$ for $24 \mathrm{~h}$ and then sectioned perpendicularly into $4 \mu \mathrm{m}$ paraffin sections. The paraffin sections were stained with hematoxylin and eosin (H \& E) for histological analysis of wound healing. Masson staining was also performed to analyze the growth status of the regenerated tissue collagen fibers during wound healing. To determine the source of GFP-positive cells in the regenerated tissues, we used double-labeled immunofluorescence staining. $\alpha$ - SMA, vimentin, and GFP antibodies (1:1000, Millipore Chemicon, Billerica, MA, USA) were used to detect endothelial cells and fibroblast cells. GFP was visualized with an FITC-conjugated secondary antibody (1:100, Santa Cruz Biotechnology, Santa Cruz, CA, USA). Smooth muscle cells of blood vessels (VSMCs) and fibroblast cells were identified with a Rhodamine-labeled secondary antibody (1:100, KPL, Gaithersburg, MD, USA). Nuclei were labeled by exposure to DAPI for $15 \mathrm{~min}$. Untreated group without ADM and MSCs was served as the control group. Wound samples in control group were processed with the same double-labeled immunofluorescence staining. Images were obtained with a Zeiss LSM 510 confocal microscope (Carl Zeiss, Jena, Germany). Capillary density was evaluated by examining three random fields of each section ( $\mathrm{n}=$ 5) after immunofluorescence staining of VSMCs with the $\alpha$-SMA antibody. The fluorescence intensity of the vimentin antibody represents the fibroblast content [35]. Fluorescence intensity was processed and analyzed by Image J.

\section{Statistical analysis}

The experimental data were presented as the mean \pm SD. Statistical analysis was performed using SPSS19.0 statistical software. The differences between two groups were evaluated using unpaired Student's t tests. Values of $\mathrm{P}<0.05$ were considered statistically significant.

\section{Results}

Stable expression of GFP fluorescence in mice

Although it was expensive and complicated to obtain GFP+-MSCs from transgenic mice, we considered this MSC line to be the best candidate for the current study due to their stable retention of the GFP tag during the entire developmental period of the transgenic mice. The transgenic mice we used showed obvious fluorescence characteristics when they were imaged using a live imaging apparatus (Fig. 1A). Eight different organs were removed (Fig. 1B), and the expression of GFP in these organs was evaluated by q RT-PCR and western blotting. The results indicated that GFP fluorescent signals were detected in all organs (Fig. 1C) and that the level of GFP expression was highest in the liver (Fig. 1D and E).

Characterization of MSCS

After five passages, MSCs were imaged under light and fluorescence microscopes (Fig. $2 \mathrm{~A}$ and $2 \mathrm{~B}$ ). The cells clearly exhibited normal spindle-shaped morphologies and strong 


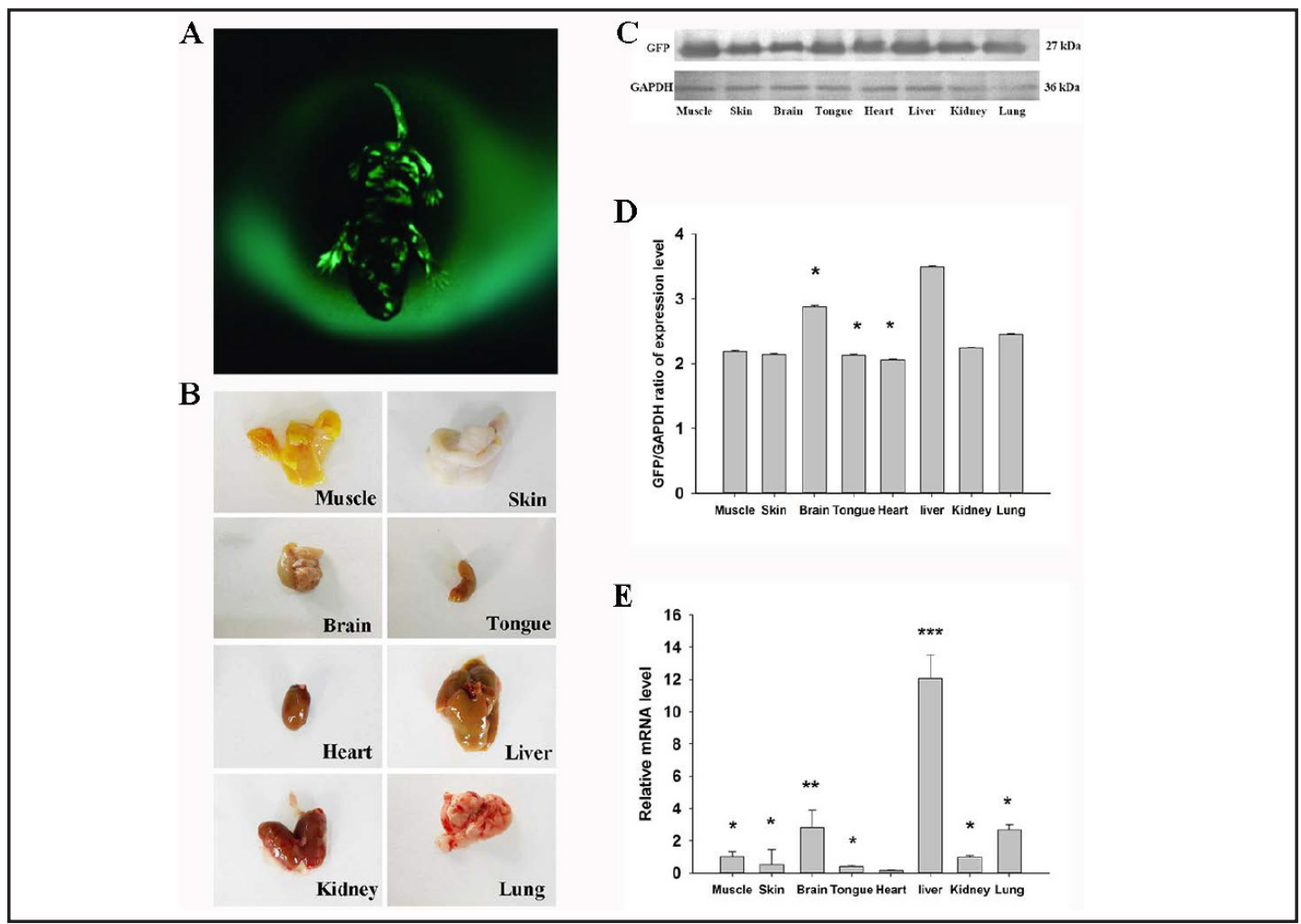

Fig. 1. Expression of GFP in different organs of the transgenic mice. (A) Imaging of GFP transgenic mice (10 days old) using a live fluorescence imaging system. (B) Muscle, skin, brain, tongue, heart, liver, kidney, and lung from the GFP+ mice. (C) Comparison of GFP expression levels in each organ via western blot analysis. (D) Statistical analysis of the expression of GFP. Among all the organs, the expression of GFP in the liver was relatively high. (E) Relative changes in mRNA expression of GFP in different organs of the transgenic mice. Similar to the relative protein content, the expression of mRNA GFP in the liver was also highest. Error bars represent $\mathrm{SD}(\mathrm{n}=5) .{ }^{*} \mathrm{P}<0.05,{ }^{* *} \mathrm{P}<0.01,{ }^{* * *} \mathrm{P}<0.001$.

fluorescence characteristics. Fluorescence-activated cell sorting (FACS) analysis of the MSCs indicated that they were negative for CD45, CD34 and CD14, but strongly expressed typical surface antigens, such as CD29, CD90, CD105 and CD44 (Fig. 2C).

\section{Characterization of acellular scaffold}

After removing the epidermis and cellular components from the dermis of the skin collected from ten-week-old mice, we obtained white, round and porous acellular scaffolds. (Fig. 3A). SEM imaging of the ADM scaffolds showed that the acellular scaffolds were composed of distributed fibrous structures and that the fibers were arranged in a net shape, forming a gap of different sizes (Fig. 3B). Single ADM scaffolds and MSC-ADM scaffolds were imaged by TPLSCM (Fig. 3C and D). The MSCs survived and grew well on the scaffolds. The MSCs gradually invaded deeper layers of the acellular dermal scaffolds with prolonged culture time (white arrows).

Skin wound modeling and wound repair analysis

The process of establishing the mouse skin wound model is illustrated in Fig. 4A. Male BALB/c mice (8-10 weeks old) were anesthetized by intraperitoneal injection of chloral hydrate solution. After the mice were completely anesthetized, they were fixed on an operating table, and a circular area with a diameter of $7 \mathrm{~mm}$ was marked on the backs of the mice. Then, a full-thickness cutaneous wound was made on the selected circular area using a biopsy punch with ophthalmic scissors and tweezers. The wounds were treated with 


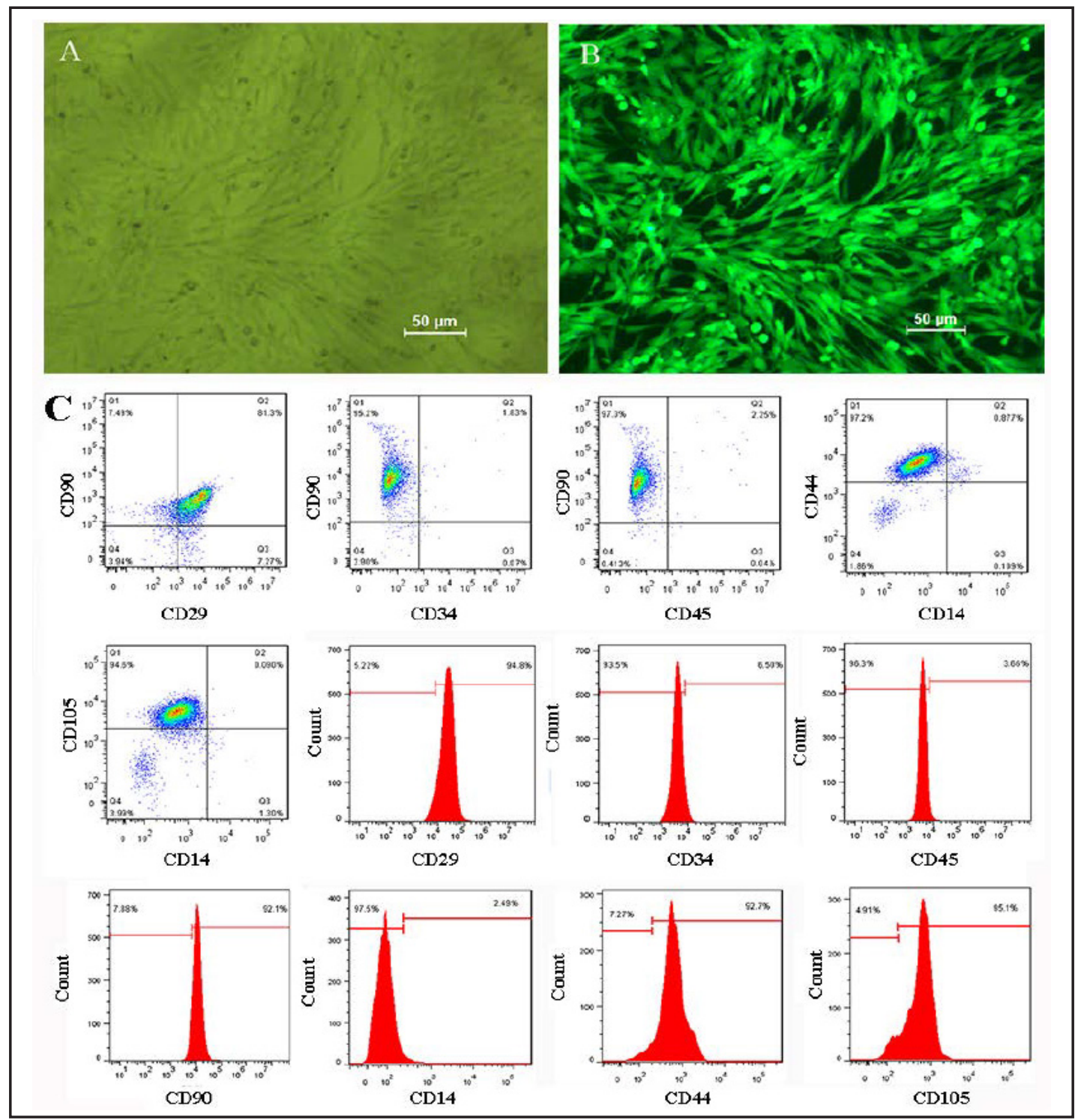

Fig. 2. Characterization of MSCs. (A and B) MSCs images taken using a microscope (Scale bar, $50 \mu \mathrm{m}$ ). (C) Flow cytometry analysis of specific cell surface molecular markers of the MSCs. The result showed that the MSCs were positive for surface antigen markers, such as CD29, CD90, CD105 and CD44, and negative for CD45, CD34 and CD14.

MSC-ADM scaffolds, and then Comfeel transparent dressings were used to cover the wound area. The wounds of control group were without any treatment, besides the usage of Comfeel transparent dressing and medical adhesive tape. As the treating time prolonged, wound healing in different groups got more and more significant. The wounds treated with MSC-ADM showed better therapeutic effects than that of control group (Fig. 4B). The representative $\mathrm{H}$ \& E images of wound sites in MSC-ADM and control group on different treatment days of 3, 5, 7, 14, 21 and 28 were shown in Fig.4C. Regeneration of skin appendages, such as hair follicles and sweat glands, could be observed on days 14, 21 and 28 of the histological process of wound healing via H \& E staining in MSC-ADM group, while almost 28 days were necessary for control group. By day 28, almost-complete skin structures that resembled normal skin could be observed in MSC-ADM group (Fig. 4C). Wound closure was calculated by the Image J software, and the result revealed a strong increment of wound healing in wounds treated with MSC-ADM compared with untreated control group (Fig. 4D). The mean percentage of 

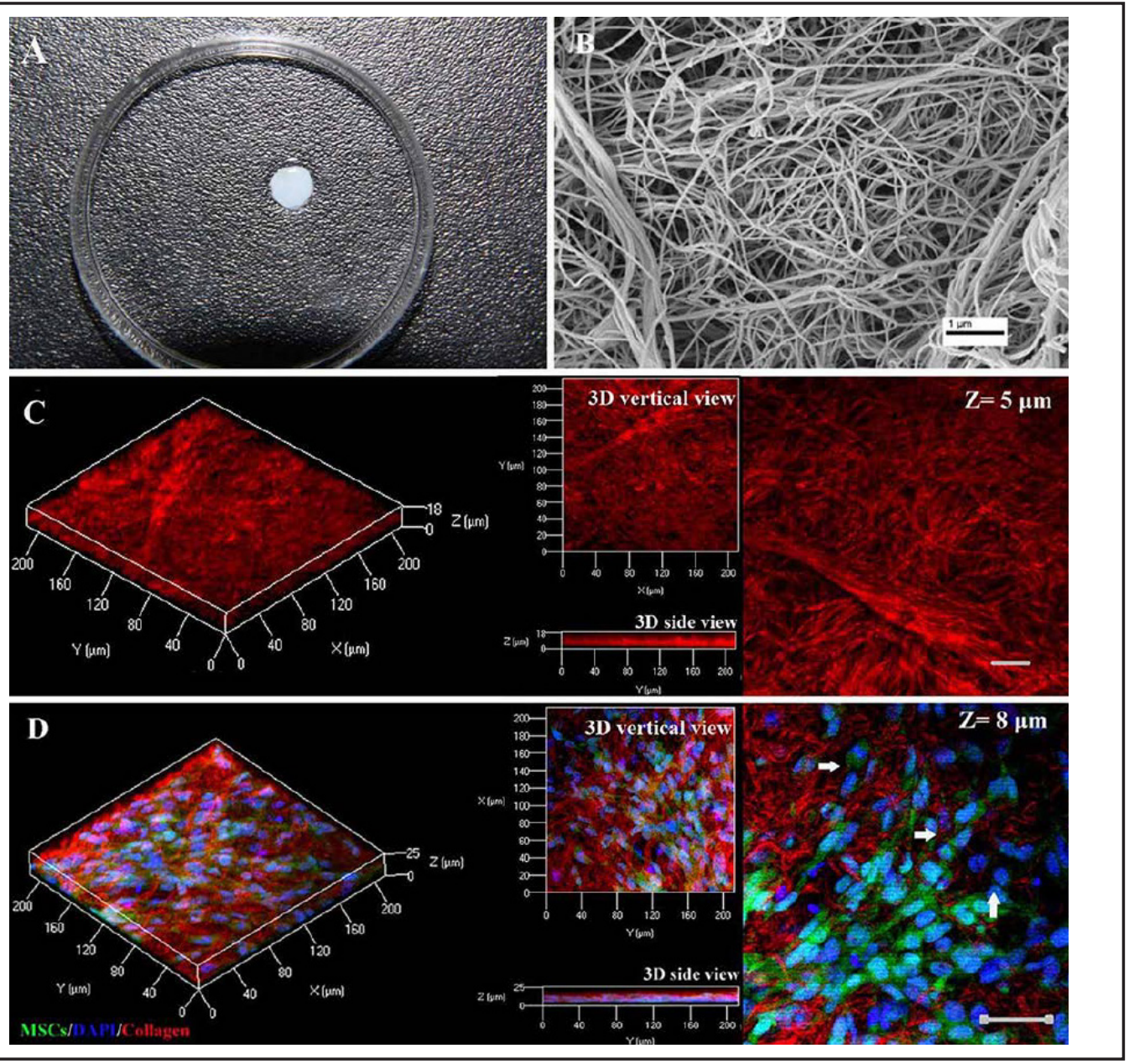

Fig. 3. Characterization of acellular scaffolds. (A) The appearance of the acellular scaffolds (7 $\mathrm{mm}$ in diameter). (B) SEM image of an ADM scaffold (Original magnification, 30000x. Scale bar, $1 \mu \mathrm{m}$ ). (C) TPEF-SHG 3D images of ADM scaffolds $(20 \mathrm{x}, 50 \mu \mathrm{m})$. Right shows TPEF-SHG imaging of ADM scaffolds $5 \mu \mathrm{m}$ below the ADM surface taken using a laser wavelength of $820 \mathrm{~nm}$. (D) TPEF-SHG 3D scanning images of an MSC-ADM complex cultured in MSC medium for 2 days. Right shows TPEF-SHG imaging of an MSC-ADM complex $8 \mu \mathrm{m}$ below the ADM surface. Green, red and blue represent MSCs, collagen and nuclei, respectively, (40x, $50 \mu \mathrm{m})$.

wound closure was $91.9 \pm 2.5 \%$ in MSC-ADM group and $83.1 \pm 2.0 \%$ in control group at postoperative 28 days.

Dynamic change in MSCs during wound healing revealed by TPEF-SHG imaging analysis and western blotting

To observe the behavior of MSCs during wound repair, regenerative skin tissues located at the wound sites were collected on days 3, 5, 7 and 14 after MSC-ADM scaffolds were implanted into the skin wounds and immediately imaged by TPLSCM. In addition, the wounds of control group were also imaged by TPLSCM (Fig. 5A). By evaluating the GFP and SHG signal intensities of the corresponding samples from the photographs shown in Fig. 5A, we obtained two curves to depict the changes of the number of MSCs and collagen accumulation at different time points (Fig. 5C and Fig. 5B). The result revealed that the collagen content markedly increased in both two groups as treatment time was prolonged and the content of MSC-ADM group was higher than that of control group at the same healing day (Fig. 5B). The number of GFP+-MSCs gradually decreased (Fig. 5C) with time. This result was further confirmed by western blot analyses (Fig. 5D and 5E). The expression level of 

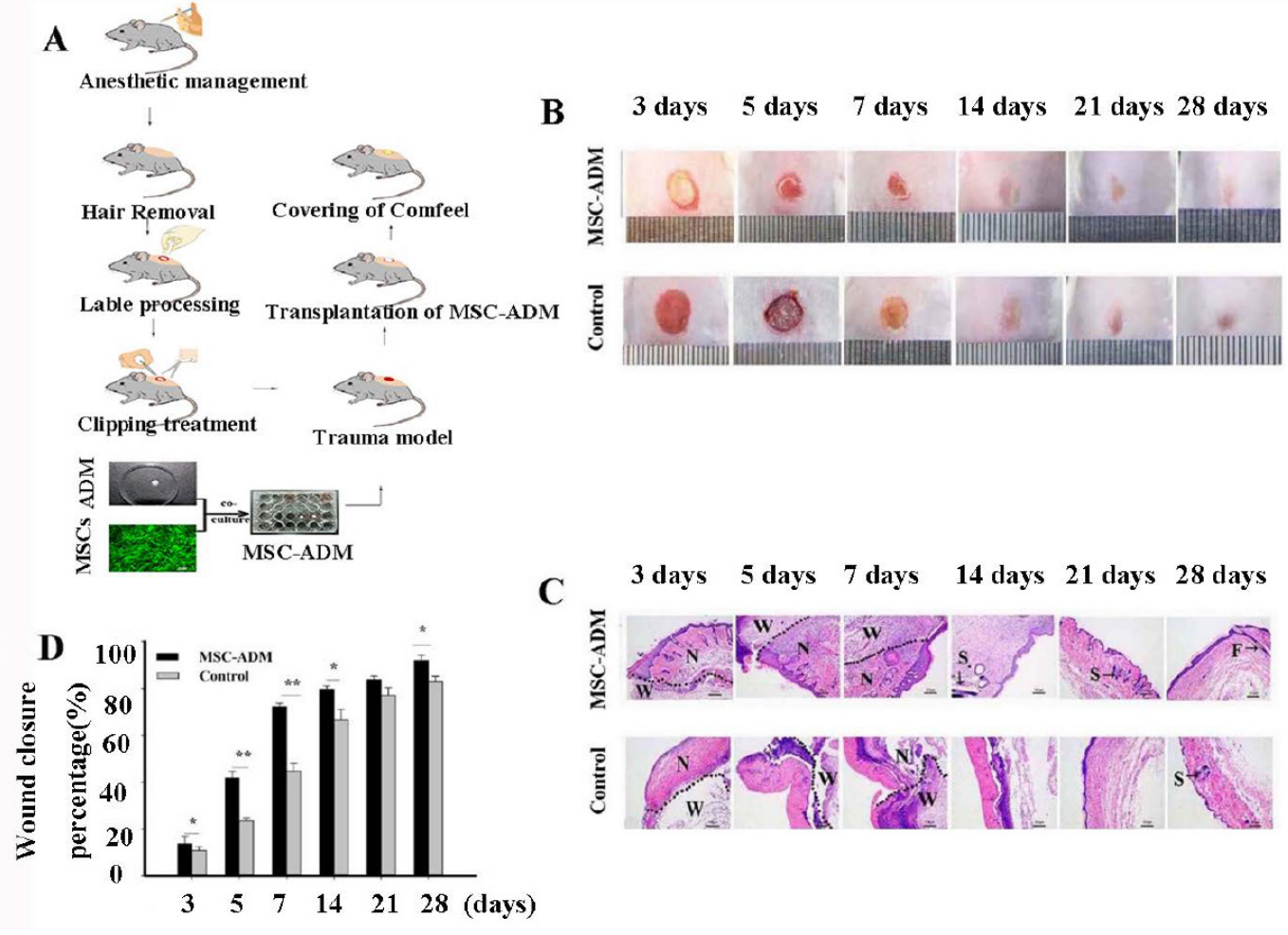

Fig. 4. Skin wound modeling and wound repair analysis. (A) Sketch of the establishment of wound model. (B) Images of wound areas in MSC-ADM group and control group on days 3, 5, 7, 14, 21 and 28 (after removal of Comfeel transparent dressings). (C) Representative H \& E-stained images of the wound sites in MSC-ADM group and control group. The histological process of wound healing was demonstrated, including the wound scab, eschar shedding and skin appendage regeneration (Original magnification, 10x. Scale bar, $100 \mu \mathrm{m}$. N, normal site. W, wound site. S, sebaceous gland. F, hair follicle). (D) The increased percentage of wound closure at different treatment times (days 3, 5, 7, 14, 21 and 28) in both groups. Error bars represent $\operatorname{SD}(n=5)$.

GFP was significantly decreased in the wounds and approached zero on days 14 after wound induction.

Dynamic change in MSCs during wound healing revealed by PCR analysis

To determine the cause of the disappearance of fluorescent signals in previous experiments, whether due to gene silencing or cell apoptosis, we extracted the genomic DNA from healing tissues and amplified the GFP gene sequence from these DNA samples (Fig. 6A). PCR results showed that Lanes 1 to 4 (day 3 to 14) had bright target bands corresponding to a size of approximately $260 \mathrm{bp}$. However, Lane 5 (day 21) and Lane 6 (day 28) had no target bands. The brightness of the target band became weaker with time. The relative content of DNA also presented a gradually decreasing trend (Fig. 6B). Strip brightness (relative DNA content) on days $5,7,14,21$, and 28 were calculated relative to that on day 3 . The PCR products of the bands were sequenced, and base peak maps are displayed (Fig. 6C). The PCR products were sequenced in the forward and reverse directions. The size of the coding sequence of the target gene was $720 \mathrm{bp}$. Comparing the results of sequencing with the GFP coding sequence, the base sequence of the amplified product corresponded to approximately the 250th to 500th bp of the GFP coding sequence. Base sequence alignment was performed using CLUSTALX2 software (Fig. 6D). The forward and reverse sequences were each compared with the GFP coding sequence. The matching rate reached 98\% (white blank blocks indicate no match of the bases). Thus, the DNA amplification products before day 14 were GFP. This

\section{KARGER}




\section{Cellular Physiology and Biochemistry

Fig. 5. The expression of GFP was gradually decreased with prolonged treatment time. (A) Activities of fluorescent cells in MSC-ADM scaffolds transplanted into the wound site on days 3, 5, 7 and 14 . Green and red represent the $\mathrm{GFP}^{+}$-MSCs and collagen in left and middle columns, respectively, and their merge in the right column. The wounds of control group imaged by TPLSCM showed the changes of collagen intensity on days $3,5,7$ and 14. (Original magnification, 40x. Scale bar, $20 \mu \mathrm{m}$ ). (B) SHG intensity of collagen at different time points with increased treatment times in MSCADM group and control group. (C) Fluorescence intensity with treatment time. (D) Compa-
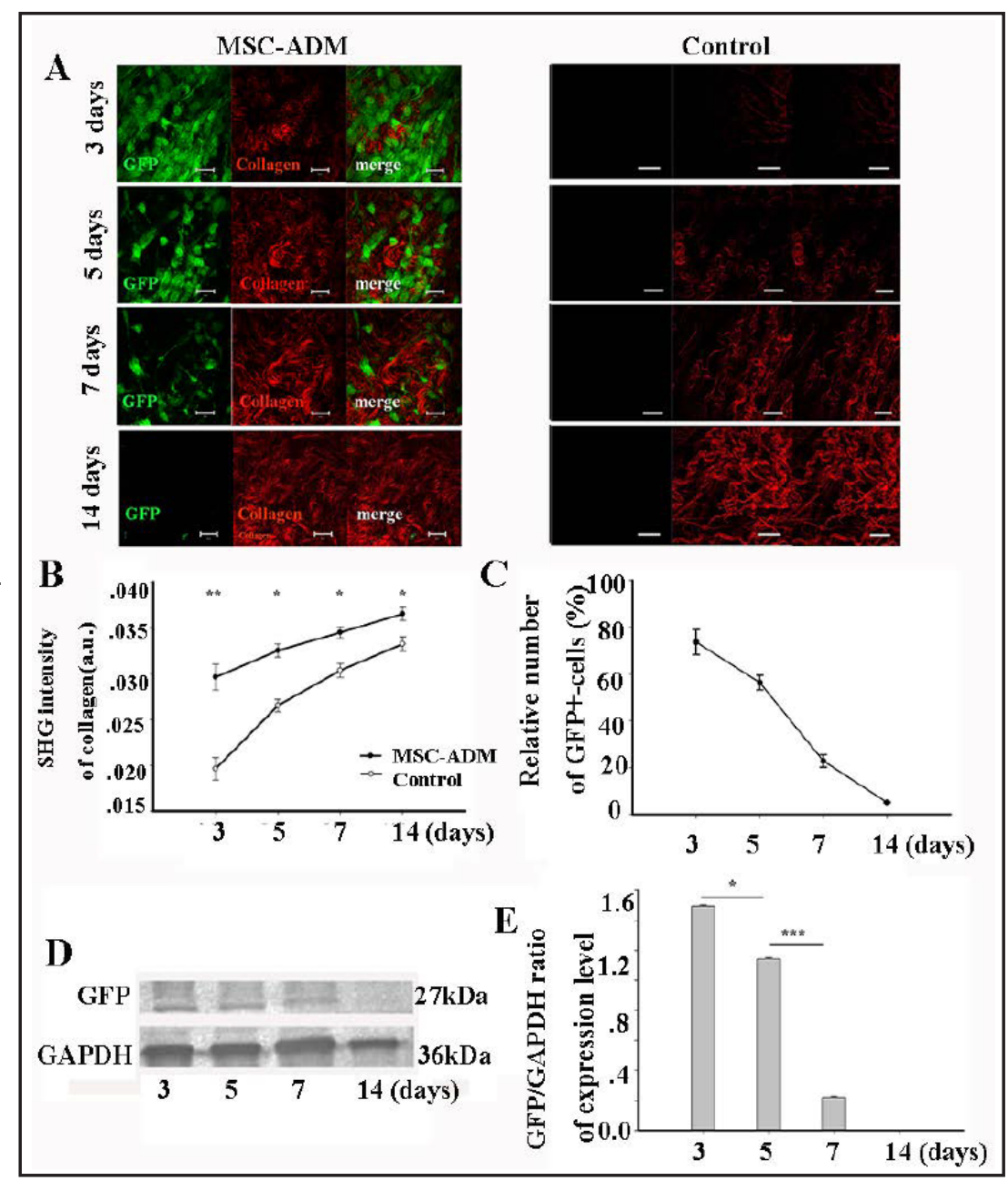

rison of GFP levels in each group (3, 5, 7 and 14 days) via western blot analysis. (E) Statistical analysis of the expression of GFP. The data are expressed as the mean values, and the error bars represent SD $(n=5)$. ${ }^{*} \mathrm{P}<0.05,{ }^{* *} \mathrm{P}<0.01,{ }^{* * *} \mathrm{P}<0.001$.

result revealed that the GFP gene was still present on day 14, indicating that the MSCs (or the MSCs and their differentiated progeny) were alive. On days 21 and 28, the GFP gene was not detected, indicating that the fluorescent cells had undergone apoptosis.

\section{Collagen regeneration and skin remodeling}

Masson staining can provide general information and insight regarding the wound healing process after transplantation. As shown in Fig. 7A, sections of the wound site showed a loss of full-thickness skin. In the first few days, we observed the wounds of MSC-ADM group under a microscope that a dyed red scab formed in the wound. However, the accessory glands and the muscle layer did not appear in the wound. On day 14, with the disappearance of the scab, the wound skin had become smoother, and the regeneration of collagen was also more obvious. On day 21 , skin appendages, the most significant development in the process of skin healing, were reborn in the wound. On day 28 , the regenerative tissue more closely resembled normal skin. However, the regeneration structure of wounds in control group was relatively incomplete and the repair rate is comparatively slow. A collagen regeneration reaction was analyzed by double-immunofluorescence staining with fibroblast cytoskeletal protein (vimentin/VIM) and GFP (Fig. 7B). In the MSC-ADM group, we observed many GFP ${ }^{+}$ $/ \mathrm{VIM}^{+}$-cells at the wound site three days after operation, whereas the number of these cells decreased with treatment time. On day 7, a very small amount of green fluorescent protein was 


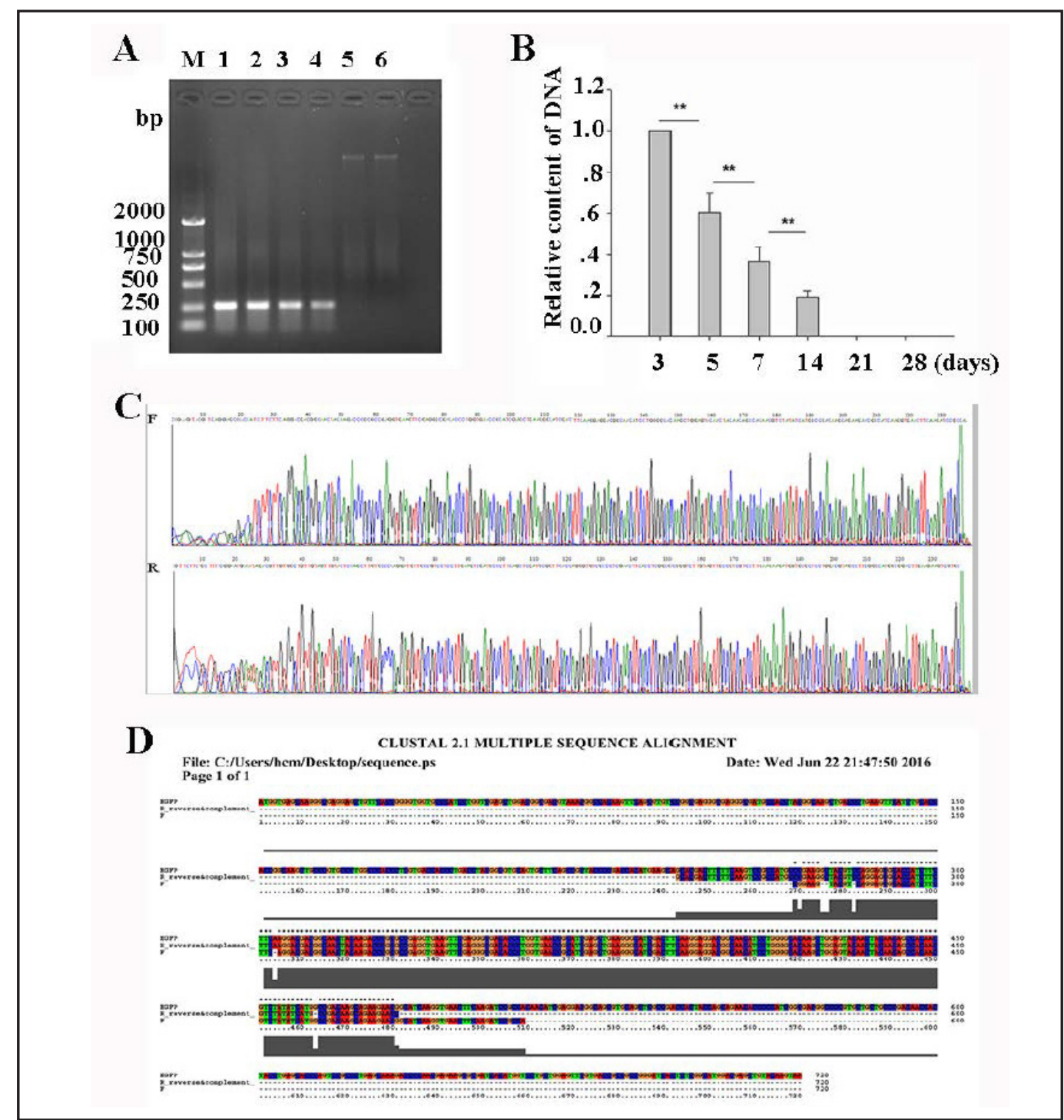

Fig. 6. Presence of fluorescent cells during wound healing. (A) Detection of PCR-amplified DNA products by 2\% agarose gel electrophoresis (M: Marker D2000; 1, 2, 3, 4, 5, and 6 correspond to skin samples collected on days 3, 5, 7, 14, 21, and 28, respectively). (B) Changes in the relative GFP DNA content in the skin tissue over time. (C) Sequence peaks of the amplified products. (D) Sequence alignment results of the amplified products and GFP sequences.

detected, and GFP became fuzzy and non-morphological. Almost no GFP could be detected on day 14 (Fig. 7B and C). The survival rate of the implanted MSCs was determined by measuring the fluorescence intensity of the cells. The relative number of fibroblasts derived from the MSCs gradually reduced; this process was accompanied with the proportion of $\mathrm{GFP}^{+} / \mathrm{VIM}^{+}-$ cells and the total VIM+-cells decreased gradually. Furthermore, the endogenous fibroblast population increased (Fig. 7C), which indicated that paracrine effects slowly played a leading role as the time of wound healing increased. However, compared with the control group, the expression levels of VIM were higher in the MSC-ADM group (Fig. 7D), and this result demonstrated that the MSC-ADM played a role in the recruitment and secretion processes during wound repair. For each detection time point, the expressions of VIM continuously increased from day 3 to day 14 in the MSC-ADM and control groups, and this change was consistent with the increasing number of fibroblasts in regenerating tissues. 


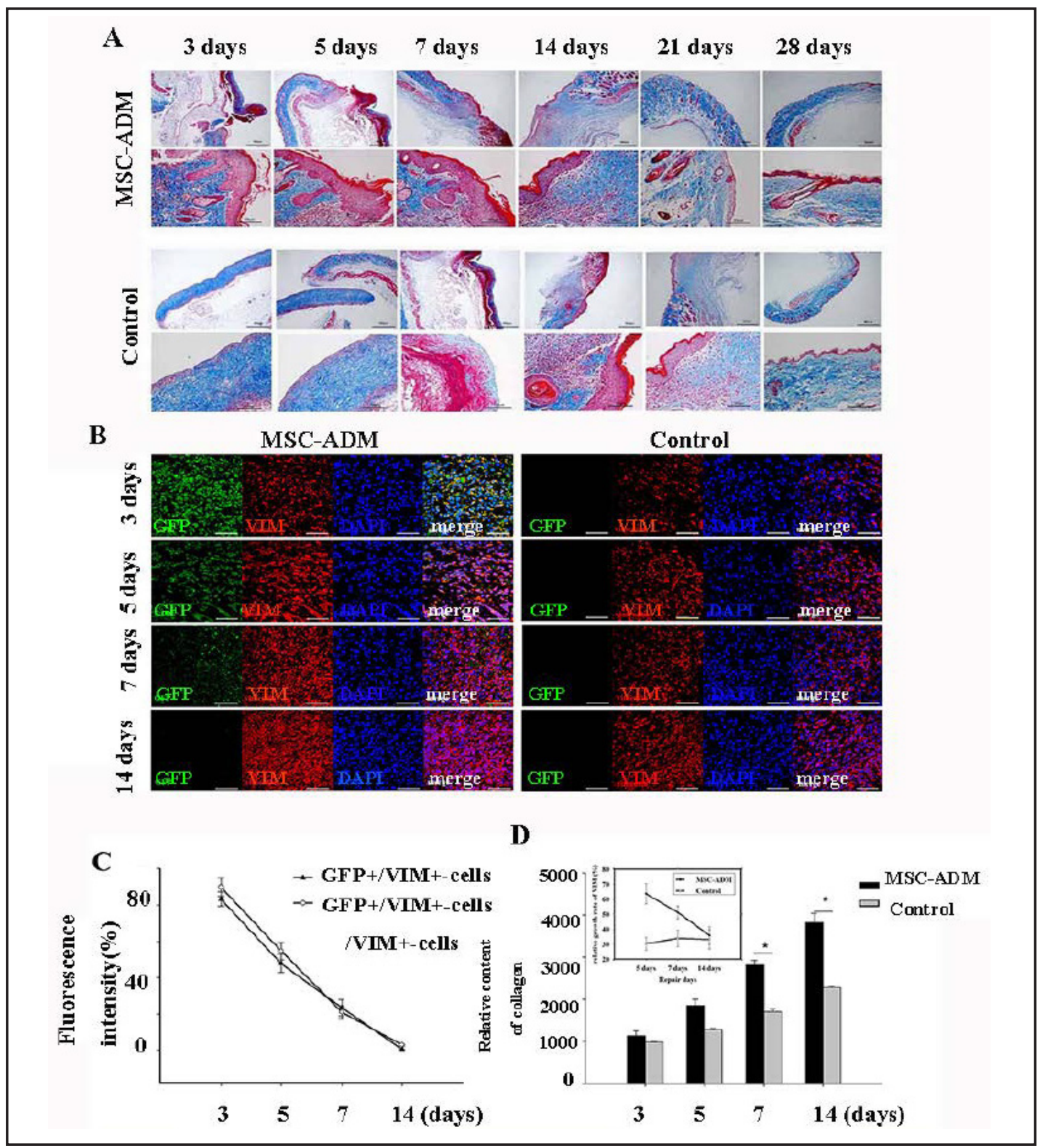

Fig. 7. Regeneration and reconstruction of skin collagen structure after treatment. (A) Masson trichrome staining of healing wounds in MSC-ADM group and control group on days 3, 5, 7, 14, 21, and 28. Original magnifications are $4 \mathrm{x}$ (the picture above of each group) and 20x (the picture below of each group). (B) TPEF imaging of the MSC-ADM group and control group. Green, red and blue represent $\mathrm{GFP}^{+}$-cells, $\mathrm{VIM}^{+}$-cells, and nuclei. (Original magnification, 40x. Scale bar, $50 \mu \mathrm{m}$ ). (C) Relative changes in the number of $\mathrm{GFP}^{+} / \mathrm{VIM}^{+}-$ cells in the wound sites at 3, 5, 7 and 14 days after transplantation. The proportion of $\mathrm{GFP}^{+} / \mathrm{VIM}^{+}$-cells to all $\mathrm{VIM}^{+}$-cells exhibited a gradually decreasing trend. (D) The relative quantitative analysis of fibroblasts of the MSC-ADM and control groups. The figure of upper left corner indicates the relative growth rate of VIM (MSC-ADM group and control group) at 5, 7 and 14 days. The data are expressed as the mean value and SD $(\mathrm{n}=5) .{ }^{*} \mathrm{P}<0.05,{ }^{* *} \mathrm{P}<0.01,{ }^{* * *} \mathrm{P}<0.001$.

\section{Angiogenesis response in the wound}

As an important part of the healing process, the angiogenesis response was analyzed by double-immunofluorescence staining with Alpha-smooth muscle actin ( $\alpha$-SMA) and GFP. The control group was only stained with $\alpha$-SMA antibody. (Fig. 8A). Three days after cell transplantation, we observed $\mathrm{GFP}^{+} / \alpha-\mathrm{SMA}^{+}$-cells in the wound site. The number of $\mathrm{GFP}^{+}$/ 


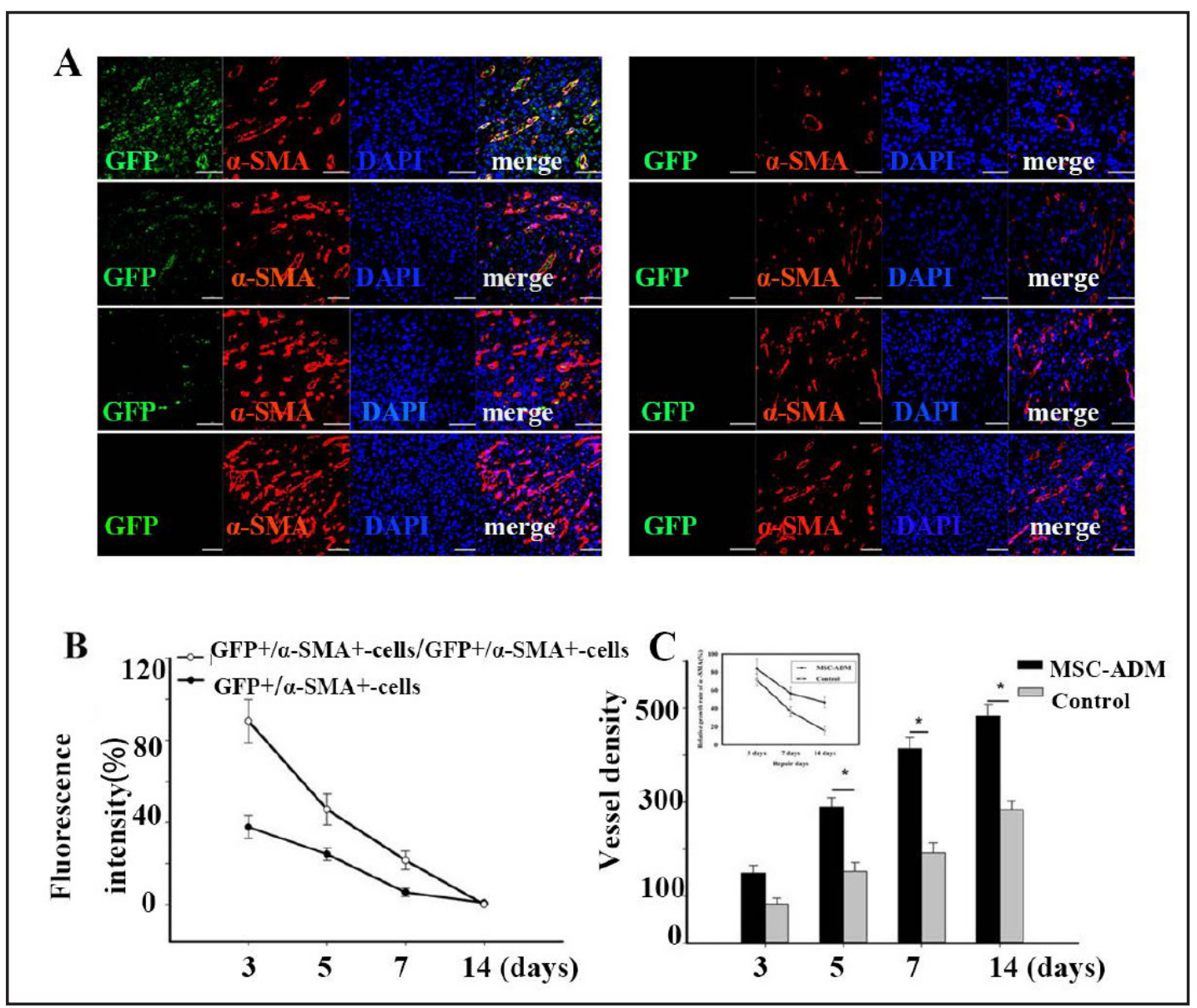

Fig. 8. The occurrence of vascular regeneration at the wound site. (A) TPEF imaging of wound tissues of the MSC-ADM and control group on days 3, 5, 7, and 14. Green, red and blue represent GFP ${ }^{+}$-cells, $\alpha$-SMA ${ }^{+}$-cells, and nuclei, respectively, (Original magnification, 40x. Scale bar, $50 \mu \mathrm{m}$ ). (B) The change in the number of $\mathrm{GFP}^{+} / \alpha-\mathrm{SMA}^{+}$-cells in the wounds on days 3, 5, 7 and 14 after transplantation. The proportion of both GF$\mathrm{P}^{+} / \alpha$-SMA ${ }^{+}$-cells to all $\alpha$-SMA ${ }^{+}$-cells in the MSC-ADM group. (C) Quantitative analysis of the vessel density of the MSC-ADM and control groups on days 3, 5, 7, and 14. The figure of upper left corner indicates the relative growth rate of $\alpha$-SMA (MSC-ADM group and control group) at 5, 7 and 14 days. The data are expressed as the mean values and SD $(\mathrm{n}=5) .{ }^{*} \mathrm{P}<0.05,{ }^{* *} \mathrm{P}<0.01,{ }^{* * *} \mathrm{P}<0.001$.

$\alpha$-SMA ${ }^{+}$-cells decreased with treatment time. Extremely few $\mathrm{GFP}^{+}$-cells were detected on day 7. On day 14, almost no GFP signals were detected. The survival of the implanted MSCs was quantified by assaying the fluorescence intensity of the cells (Fig. 8B). In addition, we also observed that the number of smooth muscle cells of blood vessels (VSMCs) that differentiated from the MSCs decreased but the number of endogenous VSMCs was increased. In addition, the proportion of $\mathrm{GFP}^{+} / \alpha-\mathrm{SMA}^{+}$-cells and the total number of $\alpha$-SMA ${ }^{+}$-cells gradually decreased in the MSC-ADM group (Fig. 8B). The results demonstrated that paracrine effects played a major role in the wound healing process. Immunofluorescence staining showed a gradual increase in the expression of $\alpha$-SMA in the wound sites on days 3, 5, 7 and 14. $\alpha$-SMA expression was higher in the MSC-ADM group than in control group (Fig. 8C).

\section{Discussion}

In the clinical treatment of acute wounds or chronic lesions of the skin, MSCs represent a promising opportunity, and a better understanding of MSC-mediated improvements 
in cutaneous repair are needed for clinical success. In the present study, we used ADM scaffolds containing GFP-tagged MSCs extracted from the bone marrow of transgenic mice to treat excisional wounds in a mouse model. Combining traditional biomedical detection techniques with an advanced optical imaging modality, we analyzed the effects and activities of MSCs during the wound-healing process.

Based on their self-renewal and multi-lineage differentiation potentials, MSCs have been confirmed to possess the capacity to improve the wound-healing process in several damaged tissues. To understand this process in detail and to ensure safety and efficacy, it is crucial to detect the fate and distribution of MSCs delivered to wound sites. GFP has already become the most suitable biomarker for tracking MSCs due to its biocompatibility, safety, nontoxicity and high detectability [36, 37]. GFP-tagged MSCs derived from transfection methods have been commonly used as donor cell sources in previous studies [36, 38, 39]. Previous results demonstrated that GFP-tagged MSCs could be traced for 4 weeks after surgical treatment [36]. In consideration of the above-mentioned findings, we used this strategy in our previous work [30] and found that almost no GFP fluorescent signals could be detected at 14 days after transplantation. Although GFP labelling of transfected MSCs can be maintained for several months in culture in vitro, we were unsure what had occurred when these MSCs were applied in real animal models. Using a gene recombination technique, the GFP gene was recombined into the mouse genome at an early embryonic stage and was stably expressed in several tissues and organs until the embryos developed to adult founders (Fig. 1A). Therefore, in our present work, MSCs extracted from the bone marrow of transgenic mice were selected as a candidate cell line based on their stable retention of GFP labeling after long-term proliferation and differentiation in vivo.

Using a two-photon laser scanning confocal microscopy platform, we first detected GFP expression in the MSCs at different healing stages $(3,5,7,14,21$, and 28 days after transplantation). The results showed that few exogenous GFP+MSCs were detected in the wound sites, and the numbers were not significantly different from our result using transfected MSCs (data not shown). To confirm this, quantitative measurement techniques were used to analyze the GFP expression in different samples. PCR and sequencing of the GFP gene revealed there were almost no exogenous MSCs or differentiated cells derived from the GFP+-MSCs that survived in the regenerative tissues after 14 days (Fig. 6). Western blotting confirmed this result (Fig. 5). Therefore, we focused on the time frame of 1 day to 2 weeks to investigate the functional mechanism of the exogenous MSCs in tissue regeneration. Thus, the wound healing process based on MSC therapy would be analogous to the natural healing process after 2 weeks.

Remarkably, our immunofluorescence analysis showed that GFP was continually expressed in VSMCs and fibroblasts until day 7 of wound healing. After 2 weeks, the wound was closed, and there was very limited expression of green fluorescent protein, as recent studies have indicated that the life expectancy of MSCs is not long after transplantation [40, 41]. Consistent with our immunofluorescence assay, VSMCs and fibroblasts derived from exogenous bone marrow cells were transient during the course of wound healing [42]. These data suggest that MSCs may not be able to provide long-term self-renewal of VSMCs and fibroblast cells. After application of MSCs for wound treatment, compared with control group, a significant increase in $\alpha$-SMA ${ }^{+}$-cells and $\mathrm{VIM}^{+}$-cells was shown in the wound, and these cells are relevant to vascular regeneration and collagen fiber structural remodeling. Although MSCs have multi-differentiation potential, they have been suggested to play a role in damaged tissue by differentiating into tissue cells instead of dysfunctional cells [43]. However, we found that the direct effects of exogenous cells on wound healing were limited. Previous studies showed that implanted MSCs exerted beneficial effects during skin wound repair and regeneration by accelerating wound healing, promoting the formation of granulation tissue and new blood vessels, regulating ECM remodeling, etc. More importantly, these beneficial effects seemed to be mediated through paracrine effects [44]. MSCs can attract macrophages, VSMCs and other types of cells to the wound site to release a variety of angiogenic factors involved in tissue repair $[45,46]$. MSCs stimulate the release of paracrine

\section{KARGER}




\section{Cellular Physiology Cell Physiol Biochem 2017;42:623-639 \\ \begin{tabular}{ll|l} 
DOI: 10.1159/000477872 & O 2017 The Author(s). Published by S. Karger AG, Basel \\
www.karger.com/cpb
\end{tabular} \\ Wang et al.: Activities and Assessment of MSCs in Wound Healing by Advanced Optical

factors, thus playing a role in the paracrine mechanism, thereby inducing the function of endogenous tissue cells $[47,48]$. Our results are also consistent with these conclusions (Fig. 7A, and Fig. 8A). It seemed that endogenous functional cells recruited from the initial exogenous MSCs still played a role in wound healing after the disappearance of the MSCs. Notably, the cell factors VIM and $\alpha$-SMA were mainly produced by endogenous VSMCs and fibroblasts, which suggests that the implanted MSCs stimulated the production of paracrine factors released at the wound site, improving skin regeneration.

It remains unclear why the implanted MSCs disappeared. The mechanisms involved in the decline and even death of stem cells are not fully understood. Most transplanted MSCs are easily lost, which may be caused by the ischemic environment in the body. The lack of blood and oxygen supply in the damaged area is also a possible cause of cell death [49]. However, a small portion of MSCs are able to temporarily escape from death, migrate to the injured site, and successfully differentiate into functional cells to participate in tissue repair [50]. Another possible route is that MSCs can quickly migrate to the damaged site, affecting other cells through paracrine effects, and participate in the process of tissue repair and immune regulation. Future studies on the intermolecular interactions between donor stem cells and host tissues will lead to the better use of MSCs for therapeutic applications and improved endogenous repair with stimulation by exogenous stem cells in combination therapies. Although the application of stem cell therapy in wound repair has generally been accepted, much work is required for the application of stem cells in therapies for patients with skin trauma.

In conclusion, the results of the present study provide powerful evidence that transplanting MSCs seeded on ADM scaffolds may be a promising cell-based therapeutic strategy for the treatment of skin wounds. We suggest that MSCs exert their effects on cutaneous wound healing from 1 day to 2 weeks after MSC transplantation. Further work is required to understand how MSCs respond to the host environment and to improve the survival and functional effect of MSCs in wound healing.

\section{Acknowledgments}

This work was supported by the National Natural Science Foundation of China (No. 81671729) and (No. 81171379).

\section{Disclosure Statement}

The authors declare that they have no interests that could influence the publication of this paper.

\section{References}

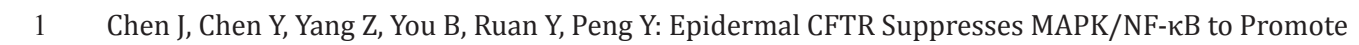
Cutaneous Wound Healing. Cell Physiol Biochem 2016;39:2262-2274.

-2 Zhou T, Yang Z, Chen Y, Huang Z, You B, Peng Y, Chen J: Estrogen Accelerates Cutaneous Wound Healing by Promoting Proliferation of Epidermal Keratinocytes via Erk/Akt Signaling Pathway. Cell Physiol Biochem 2016;38:959-968.

-3 Smith AN, Willis E, Chan VT, Muffley LA, Isik FF, Gibran NS, Hocking AM: Mesenchymal stem cells induce dermal fibroblast responses to injury. Exp Cell Res 2010;316:48-54.

4 Maharlooei MK, Bagheri M, Solhjou Z, Jahromi BM, Akrami M, Rohani L, Monabati A, Noorafshan A, Omrani GR: Adipose tissue derived mesenchymal stem cell (AD-MSC) promotes skin wound healing in diabetic rats. Diabetes Res Clin Pract 2011;93:228-234.

5 Liu L, Yu Y, Hou Y, Chai J, Duan H, Chu W, Zhang H, Hu Q Du J: Human umbilical cord mesenchymal stem cells transplantation promotes cutaneous wound healing of severe burned rats. PLoS One 2014;9:e88348. 


\section{Cellular Physiology Cell Physiol Biochem 2017;42:623-639

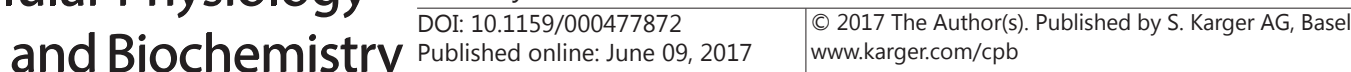

Wang et al.: Activities and Assessment of MSCs in Wound Healing by Advanced Optical Techniques

6 Rodriguez-Menocal L, Shareef S, Salgado M, Shabbir A, Van Badiavas E: Role of whole bone marrow, whole bone marrow cultured cells, and mesenchymal stem cells in chronic wound healing. Stem Cell Res Ther 2015;6:24.

7 Khong SM, Duscher D, Januszyk M, Than PA, Maan Z, Gurtner GC: Single cell transcriptomic analysis of human fetal bone marrow-derived mesenchymal stem cells in wound healing. Plast Reconstr Surg 2015;135:123-124.

-8 Tonn T, Barz D: Msc-a multipotent stromal cell in search of clinical application. Transfus Med Hemother 2008;35:269-270.

-9 Borena BM, Martens A, Broeckx SY, Meyer E, Chiers K, Duchateau L, Spaas JH: Regenerative skin wound healing in mammals: state-of-the-art on growth factor and stem cell based treatments. Cell Physiol Biochem 2015;36:1-23.

10 Nie C, Yang D, Xu J, Si Z, Jin X, Zhang J: Locally administered adipose-derived stem cells accelerate wound healing through differentiation and vasculogenesis. Cell Transplant 2011;20:205-216.

-11 Cao Y, Sun Z, Liao L, Meng Y, Han Q, Zhao RC: Human adipose tissue-derived stem cells differentiate into endothelial cells in vitro and improve postnatal neovascularization in vivo. Biochem Biophys Res Commun 2005;332:370-379.

-12 Lu F, Mizuno H, Uysal CA, Cai X, Ogawa R, Hyakusoku H: Improved viability of random pattern skin flaps through the use of adipose-derived stem cells. Plast Reconstr Surg 2008;121:50-58.

-13 Xu J, Wu W, Zhang L, Dorset-Martin W, Morris MW, Mitchell ME, Liechty KW: The Role of MicroRNA-146a in the Pathogenesis of the Diabetic Wound-Healing Impairment. Diabetes 2012;61:2906-2912.

14 Couture P, Paradis-Massie J, Oualha N, Thibault G: Adhesion and transcellular migration of neutrophils and B lymphocytes on fibroblasts. Exp Cell Res 2009;315:2192-2206.

15 Schäfer M, Werner S: Oxidative stress in normal and impaired wound repair. Pharmacol Res 2008;58:165171.

16 Lee SH, Jin SY, Song JS, Seo KK, Cho KH: Paracrine effects of adipose-derived stem cells on keratinocytes and dermal fibroblasts. Ann Dermatol 2012;24:136-143.

-17 Jeon YK, Jang YH, Yoo DR, Kim SN, Lee SK, Nam MJ: Mesenchymal stem cells' interaction with skin: Woundhealing effect on fibroblast cells and skin tissue. Wound Repair Regen 2010;18:655-661.

18 Ojeh NO, Navsaria HA: An in vitro skin model to study the effect of mesenchymal stem cells in wound healing and epidermal regeneration. J Biomed Mater Res A 2014;102:2785-2792.

19 Wagner J, Kean T, Young R, Dennis JE, Caplan AI: Optimizing mesenchymal stem cell-based therapeutics. Curr Opin Biotechnol 2009;20:531-536.

20 Chen JS, Wong VW, Gurtner GC: Therapeutic potential of bone marrow-derived mesenchymal stem cells for cutaneous wound healing. Front Immunol 2012;3:192.

21 Feng Y, Wang J, Ling S, Li Z, Li M, Li Q, Ma Z, Yu S: Differentiation of mesenchymal stem cells into neuronal cells on fetal bovine acellular dermal matrix as a tissue engineered nerve scaffold. Neural Regen Res 2014;9:1968-1978.

-22 Zhang X, Deng Z, Wang H, Yang Z, Guo W, Li Y, Ma D, Yu C, Zhang Y, Jin Y: Expansion and delivery of human fibroblasts on micronized acellular dermal matrix for skin regeneration. Biomaterials 2009;30:2666-2674.

23 Yang Y, Rossi FM, Putnins EE: Ex vivo expansion of rat bone marrow mesenchymal stromal cells on microcarrier beads in spin culture. Biomaterials 2007;28:3110-3120.

24 Ke T, Yang M, Mao D, Zhu M, Che Y, Kong D, Li C: Co-transplantation of skin-derived precursors and collagen sponge facilitates diabetic wound healing by promoting local vascular regeneration. Cell Physiol Biochem 2015;37:1725-1737.

25 Campagnola PJ, Clark HA, Mohler WA, Lewis A, Loew LM: Second-harmonic imaging microscopy of living cells. J Biomed Opt 2001;6:277-286.

-26 Graf BW, Bower AJ, Chaney EJ, Marjanovic M, Adie SG, De Lisio M, Valero MC, Boppart MD, Boppart SA: In vivo multimodal microscopy for detecting bone-marrow-derived cell contribution to skin regeneration. J Biophotonics 2014;7:96-102.

27 Zipfel WR, Williams RM, Webb WW: Nonlinear magic: multiphoton microscopy in the biosciences. Nat Biotechnol 2003;21:1369-1377.

28 Ranjit S, Dvornikov A, Stakic M, Hong S-H, Levi M, Evans RM, Gratton E: Imaging fibrosis and separating collagens using second harmonic generation and phasor approach to fluorescence lifetime imaging. Sci Rep 2015;5:13378. 


\section{Cellular Physiology Cell Physiol Biochem 2017;42:623-639

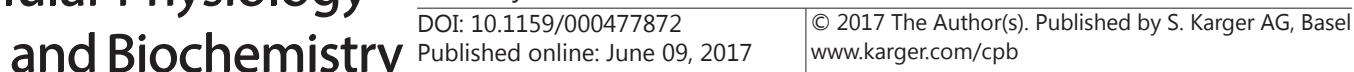

Wang et al.: Activities and Assessment of MSCs in Wound Healing by Advanced Optical Techniques

29 Zoumi A, Yeh A, Tromberg BJ: Imaging cells and extracellular matrix in vivo by using second-harmonic generation and two-photon excited fluorescence. Proc Natl Acad Sci U S A 2002;99:11014-11019.

-30 Wang Q, Jin Y, Deng X, Liu H, Pang H, Shi P, Zhan Z: Second-harmonic generation microscopy for assessment of mesenchymal stem cell-seeded acellular dermal matrix in wound-healing. Biomaterials 2015;53:659668.

-31 Han X, Liu H, Chen M, Gong L, Pang H, Deng X, Jin Y: Acellular dermal matrix from one-day-old mouse skin on adult scarless cutaneous wound repair by second harmonic generation microscopic imaging. RSC Adv 2016;6:71852-71862.

32 Phinney DG, Kopen G, Isaacson RL, Prockop DJ: Plastic adherent stromal cells from the bone marrow of commonly used strains of inbred mice: variations in yield, growth, and differentiation. J Cell Biochem 1999;72:570-585.

33 Chamberlain G, Fox J, Ashton B, Middleton J: Concise review: mesenchymal stem cells: their phenotype, differentiation capacity, immunological features, and potential for homing. Stem Cells 2007;25:2739-2749.

-34 Livak KJ, Schmittgen TD: Analysis of relative gene expression data using real-time quantitative PCR and the 2- $\Delta \Delta$ CT method. Methods 2001;25:402-408.

-35 Cheng F, Shen Y, Mohanasundaram P, Lindström M, Ivaska J, Ny T, Eriksson JE: Vimentin coordinates fibroblast proliferation and keratinocyte differentiation in wound healing via TGF- $\beta$-Slug signaling. Proc Natl Acad Sci U S A 2016;113: E4320-E4327.

-36 Guo Y, Su L, Wu J, Zhang D, Zhang X, Zhang G, Li T, Wang J, Liu C: Assessment of the green florescence protein labeling method for tracking implanted mesenchymal stem cells. Cytotechnology 2012;64:391401.

-37 Leiker M, Suzuki G, Iyer VS, Canty Jr JM, Lee T: Assessment of a nuclear affinity labeling method for tracking implanted mesenchymal stem cells. Cell Transplant 2008;17:911-922.

38 Zhang L-X, Shen L-L, Ge S-H, Wang L-M, Yu X-J, Xu Q-C, Yang P-S, Yang C-Z: Systemic BMSC homing in the regeneration of pulp-like tissue and the enhancing effect of stromal cell-derived factor-1 on BMSC homing. Int J Clin Exp Pathol 2015;8:10261.

-39 Huang C, Zhao L, Gu J, Nie D, Chen Y, Zuo H, Huan W, Shi J, Chen J, Shi W: The migration and differentiation of hUC-MSCsCXCR4/GFP encapsulated in BDNF/chitosan scaffolds for brain tissue engineering. Biomed Mater 2016;11:035004.

-40 Eggenhofer E, Benseler V, Kroemer A, Popp F, Geissler E, Schlitt H, Baan C, Dahlke M, Hoogduijn M: Mesenchymal stem cells are short-lived and do not migrate beyond the lungs after intravenous infusion. Front Immunol 2011;3:297.

41 Liu X-b, Chen H, Chen H-q, Zhu M-f, Hu X-y, Wang Y-p, Jiang Z, Xu Y-c, Xiang M-x, Wang J-a: Angiopoietin-1 preconditioning enhances survival and functional recovery of mesenchymal stem cell transplantation. J Zhejiang Univ Sci B 2012;13:616-623.

-42 Borue X, Lee S, Grove J, Herzog EL, Harris R, Diflo T, Glusac E, Hyman K, Theise ND, Krause DS: Bone marrow-derived cells contribute to epithelial engraftment during wound healing. Am J Pathol 2004;165:1767-1772.

43 Prockop DJ: Marrow stromal cells as stem cells for nonhematopoietic tissues. Science 1997;276:71-74.

44 Lee DE, Ayoub N, Agrawal DK: Mesenchymal stem cells and cutaneous wound healing: novel methods to increase cell delivery and therapeutic efficacy. Stem Cell Res Ther 2016;7:37.

45 Chen L, Tredget EE, Wu PY, Wu Y: Paracrine factors of mesenchymal stem cells recruit macrophages and endothelial lineage cells and enhance wound healing. PLoS One 2008;3:e1886.

46 Badiavas EV, Ford D, Liu P, Kouttab N, Morgan J, Richards A, Maizel A: Long-term bone marrow culture and its clinical potential in chronic wound healing. Wound Repair Regen 2007;15:856-865.

47 Tögel F, Weiss K, Yang Y, Hu Z, Zhang P, Westenfelder C: Vasculotropic, paracrine actions of infused mesenchymal stem cells are important to the recovery from acute kidney injury. Am J Physiol Renal Physiol 2007;292:F1626-F1635.

-48 Hocking AM, Gibran NS: Mesenchymal stem cells: paracrine signaling and differentiation during cutaneous wound repair. Exp Cell Res 2010;316:2213-2219.

49 Zhu W, Chen J, Cong X, Hu S, Chen X: Hypoxia and serum deprivation-induced apoptosis in mesenchymal stem cells. Stem Cells 2006;24:416-425.

50 Almalki SG, Agrawal DK: Key transcription factors in the differentiation of mesenchymal stem cells. Differentiation 2016;92:41-51. 